\title{
Chapter 11 \\ The Response of Higher Education \\ Institutions to Global, Regional, \\ and National Challenges
}

\section{The Transformation Plan of the University of Bahrain 2016-2021 as a Case Study}

\section{Riyad Y. Hamzah}

\begin{abstract}
Higher education - as many other sectors - is challenged by the dynamics of the global and local socio-economic influencing our lives, economy, environment, and lifestyle. For instance, currently existing jobs and skills are expected to be replaced by super-fast artificial intelligent cloud-based employees. Traditional higher education system and institutions eagerly pursuing transformation to cope with the current and future demands in skills, teaching and learning, research, technology, funds amongst other demanding factors of our world. This paper showcase the University of Bahrain and present how the University is transforming to address the global, regional, and national challenges it is facing today. This Paper describes the key pillars and the key performance indicators of the Transformation Plan 2016-2021 of the University of Bahrain to respond to those challenges. The Transformation Plan is inspired by the Bahrain Economic Vision 2030. Furthermore, the Plan is aligned to the National Higher Education Strategy 2014-2024, and the National Research Strategy 2014-2024. The Transformation Plan also is in alignment with the national endeavors to achieve the United Nations Sustainable Development Goals 2030.
\end{abstract}

Keywords Higher education • University $\cdot$ Strategy $\cdot$ Challenges $\cdot$ Skills $•$ Bahrain • GCC

\subsection{Introduction}

Higher Education Institutions (HEI) face numerous challenges in the 21st century as economics, environment, demographics, political, labor market, technological, as well as social and health issues, are rapidly changing. HEIs, therefore, need to be responsive to the opportunities and challenges set by these issues, which are shaping the higher education sector and the future of employment. Universities need

\footnotetext{
R. Y. Hamzah (凶)

University of Bahrain, Zallaq, Kingdom of Bahrain

e-mail: rhamzah@uob.edu.bh 
to have unique responses to these factors in order to maintain their competitiveness and quality of education. The competitiveness of institutes of higher education will depend upon their responsiveness to these variables of change.

The University of Bahrain, established in 1986, is the national flagship university of the Kingdom of Bahrain with an enrollment of more than twenty-eight thousand five hundred $(28,500)$ students and over eight hundred (800) faculty members. It is comprised of nine different colleges offering ten doctoral degrees, twenty-six masters, and forty-seven bachelors programs, in addition to eight postgraduate and fourteen associate diplomas.

In 2016, the University of Bahrain launched a strategy plan designed to address the challenges of the 21st century, namely: Transformation Plan 2016-2021. The Plan was developed to incorporate the goals of the Bahrain Economic Vision 2030 (2008) of striving to develop an efficient and effective government, a robust knowledgeeconomy that benefits the people of the Kingdom, and a just and thriving society. It further integrates the themes of the National Higher Education Strategy 2014-2024 of enhancing the overall quality of higher education in Bahrain to:

- graduate job-ready students, professionally, and personally, and to enable them to fulfil their potential and contribute to society;

- aligning Bahrain's higher education sector to meet current and future regional and national priorities;

- improving the linkages between higher education, vocational and continuing education to provide equitable and strategic access;

- leveraging the newest trends in education technology to leap Bahrain's higher education sector;

- creating an entrepreneurship ecosystem for students in Bahrain; and

- leveraging research to enhance the overall competitiveness of Bahrain's economy.

The Plan also incorporates the objectives of the Bahrain's National Research Strategy, launched in 2014, to:

- participate in the establishment of a national research governance infrastructure;

- improve public awareness and understanding of research and innovation;

- address national research priorities, strengthen the university's research capacity; and

- strengthen the integration of the university programs with industry, international research institutions, and entities focused on Bahrain's economic and social priorities.

The Plan further is in alignment with the kingdom's endeavors to achieve the UN Sustainable Development Goals 2030 (UNESCO, 2017).

This Paper present the University of Bahrain as a case study to discuss the ways and means in which the University is addressing these challenges through its Transformation Plan. The Paper discusses the key pillars of the Plan, as well as the key performance indicators used to assess its progress towards its goals. 


\subsection{Transformation Plan}

As new technologies emerge, universities must rethink the way learning and teaching is being conducted. Universities not only need to be reactive to the ever-changing external environment, but also become proactive pioneers to provide cutting-edge solutions addressing regional and global challenges. Today's educators must meet the needs of a new generation of learners aspiring to thrive and contribute in an increasingly interconnected complex world. This provides new challenges for academics, and demands that universities must constantly evolve and innovate to meet the changing needs of academia, employers, and millennial learners.

The traditional operations of universities are currently challenged as higher education institutions loose pace with dynamically changing demands. The rapidlychanging external environment led by technology is transforming learning, teaching, and research. Students and the wider society require year-round access to high quality programs and flexible modes of delivery. The regional economic context of the Gulf Cooperation Council (GCC) and challenges arising with the demands to develop and foster the private sector are also challenges that the University must respond to by focusing on producing a high quality and skilled human capital. Gaining international research impact is achieved by targeted and innovative approaches to research through international collaboration.

The impact of the University as the national university goes far wider than teaching and research. The graduates of the University are the number one choice of employers in Bahrain, the University is ranked in the top 500 globally for employer reputation according to the 2019 QS World University Rankings, and it has a flock of alumni who are leading nationally, regionally, and internationally.

Economic growth and community expectations drove the University of Bahrain to rethink its approach not just toward students but also to include faculty and staff members, industry, society and stakeholders in terms of brand, marketing, and international profile. The Transformation Plan aims to build a bridge to the future and provide a strategic roadmap to ensure that its graduates are sufficiently prepared and equipped to contribute to the social and economic growth of Bahrain by creating the next generation of leaders, influencers, entrepreneurs and innovators. The Transformation Plan has seven key pillars, which are as follows:

1. World-class Learning and Teaching: to transform learning and teaching philosophy to be responsive to changes in technology, labor market needs and the national and economic priorities.

2. Leading Edge Human Capital: to develop highly knowledgeable and skilled human capital by offering programs that will act as the catalyst for student success.

3. Research with National and Regional Impact: to concentrate on research that will contribute to national and regional priorities in areas such as renewable energy and water and food technologies. 
4. A Dynamic, Innovative, and Entrepreneurial Environment: to become a competitive, efficient and entrepreneurial organization that thrives through developing an innovation culture through its people, policies and systems.

5. Local Engagement and International Reputation: to enhance local engagement and international reputation by becoming a driver for collaboration and partnerships.

6. Bahrain's Economic Diversification and Growth: to bridge the skills gap and place the university as the leading talent pool in the region.

7. A Transformative Environment: to transform the university to host a modern, inspiring and technology-led campus.

The Transformation Plan focuses on internationalization to: create global citizens, develop relations with industry in order to be more innovative and entrepreneurial, widen its academic specialties, promote lifelong learning, and produce research that has regional and international impact. The Plan focuses on a number of areas, including establishing a Unit for Teaching Excellence and Leadership to advance teaching methods, develop innovative pedagogy, and develop the teaching skills of faculty. Technology is employed not only to enhance learning and teaching, but also to create a smart campus populated with skilled and able professionals. Faculty and staff members alike are equipped with the critical digital skills, which has been enforced by the development of a Digital Literacy Certificate for all members.

\subsection{Sustainable Development Goals and Innovation}

The pressure of economic growth against failing oil prices and diminishing resources means that economies and organizations of the GCC need to be more dynamic, agile, and productive than ever before. The GCC region faces dwindling natural resources, stretched public funding, and increasing populations. The population is increasingly shifting to living in cities which consequently is putting excess strain on infrastructure of many cities. The population of the GCC has doubled over the past 20 years to reach 51 million in 2015. The GCC is one of the most highly urbanized parts of the world with $85 \%$ of its populations living in cities today, expected to rise to $90 \%$ by 2050 (PWC, 2017).

These issues are compounded by the environmental challenges that the GCC currently faces. The Middle East and North Africa (MENA) region as a whole currently faces significant environmental issues, water shortages, drought areas, air pollution, climate change, and rising energy consumption. The lack of access to sufficient clean water threatens in many ways mankind, and can lead to the spread of disease. Water scarcity and pollution threaten agriculture and food production. The Arab Forum for Environment and Development produced a report discussing these challenges to be faced by the region in the next ten years (AFED, 2017).

Considering these regional environmental issues, universities in the region need to comply with international and environmental requirements, including policies 
towards reducing the carbon footprint by moderating carbon emissions and energy consumption, controlling the waste generated, smarter use of air conditioning, promoting recycling as good practice, and introducing transport regulations on student and faculty car usage (endorsing public transport). Moving forward, it is critical that universities must take responsibility for their environmental footprints and aspire to integrate environmental management good practice into daily business. Higher education must aim for eco-friendly campuses by refurbishing, designing, and managing existing and future campuses.

In 2016, the University of Bahrain began to subscribe to the Green Metric ranking, ranked 307 globally in 2017 (Green Metric, 2017), in order to monitor its own progress and its key performance indicators towards becoming an environmentally friendly campus (Hamzah, Alnaser, \& Alnaser, 2018).

As Bahrain's population increases, it is clear that technology is being used in the development of smart towns with energy efficient housing and roads designed to minimize traffic congestion through the use of interconnected traffic signals. The greatest potential savings are in energy consumption. Total household electricity spending in the MENA region is expected to reach approximately $\$ 250$ billion by 2025. Technology such as connected thermostats and remotely controlled lighting could save around $10-15 \%$, in addition to saving time through automated tasks.

Technology plays a significant role in innovation with the potential to address many of the regional challenges. Large investments in innovation, such as the partnership with Amazon Web Services, are testament to the growing importance of innovation on the business and national agendas of countries within the MENA region. Promptly, the University has established one of the first Amazon Academies in the region.

The rise of the Fourth Industrial Revolution has created talent mismatches, with $65 \%$ of employers and 59\% of job seekers in the MENA region believing that a skills gap exists (Bayt.com, 2017). Clearly there is a disconnect between the requirements of new jobs driven by technology and the skill sets of graduates. The Fourth Industrial Revolution is disrupting the way work is being done, how public services are delivered and how economies are being shaped. We live in permanent disruption where the mantra is to innovate or become obsolete. According to the Future of Jobs and Skills in the Middle East and North Africa report, (World Economic Forum, 2017) the skills relevant in industry include complex problem solving, critical thinking, creativity, people management, coordinating with others, judgement and decisionmaking, service-oriented, negotiation, and cognitive flexibility. Numerous employer surveys suggest that the majority of students graduating from the education system lack these skills.

Graduates need to develop the relevant skills that allow them to compete in a competitive and dynamic job market, as one of the biggest challenges in the region is youth unemployment as a result of rapid change in labor market requirements. Universities must, therefore, revise how they operate, and investment in technology, teaching and career advice is critical to ensure skilled graduates and a productive labor market. 
The Future of Jobs and Skills in the Middle East and North Africa analysis (World Economic Forum, 2017) found that, by 2020, 21\% of core skills in the countries of the GCC will be different compared to skills that were needed in 2015. The report listed the top ten skills needed for 2020 and beyond. Heading this list are skills that universities do not typically prioritize, such as: problem-solving, creativity, teamwork, and people management. Therefore, a new way of delivering higher education is required, a paradigm shift.

Digital and related skills are predominately required by employers. The Transformation Plan adopts the premise that all students and teachers should have digital literacy as a minimum requirement. Teaching and learning should be repositioned to encourage inquiry-based learning and to encourage project participation. Assessment of students should focus on application of knowledge and skill development, not just passing exams. The University has responded by investing in upgrading teaching and curriculum development, in addition to re-designing student assessment, putting more emphasis on internships and industry engagement to shape learning experiences for students.

As some economic sectors shrink, others will grow, especially those powered by technology. The rise of digital labor markets will mean that graduates must not only have core digital skills but also must have entrepreneurial skills to become social marketers and have a range of communication and softs skills that sets them apart.

Universities are required to move to a multi-disciplinary approach or even transdisciplinary to allow students to explore creativity and nonlinear learning patterns that represent the digital age. Science, Technology, Engineering, and Mathematics (STEM) education is vital. In a world populated with super-fast and smart computers, however, STEM coupled with creativity can be considered as even more critical, STEAM (STEM + ARTS), the fusion of science and technology with creativity and liberal thinking.

Innovation led by technology can aid the region in addressing many of the sustainability challenges currently faced. It can enable countries to ensure that infrastructure meets the demands of society and consumers. It can potentially tighten standards on consumption, especially energy. It can help to make it easier setting up businesses and to incubate startups. Universities must not only embrace technology but also use it effectively to help create innovative solutions that will help to solve many of our sustainability issues. Here the role of technology transfer is vital. Taking academic research and using technology to commercialize is one way to deploy solutions on a wider and faster scale.

The impact of this is reflected in the 2017-18 Innovation Pillar from the World Economic Forum's Global Competitiveness Index which shows Bahrain's improvement in 7 out of 8 indicators, and driving this culture of innovation are the universities, significant improvements in innovation, capacity, quality of research institutes, and university/industry collaboration, as shown by the World Economic Forum Innovation pillar (World Economic Forum, 2018). As a result, Bahrain is emerging as a hub for Fintech entrepreneurship, powered by its skilled, labor market ready graduates, with large corporations such as Amazon Web Services and Huawei setting up 
their regional headquarters in Bahrain to enable them to tap into this rich dynamic potential.

The Transformation Plan has provided a real opportunity to examine the systems, architecture and infrastructure needed for universities to contribute to the economies, public services and societies of the Kingdom of Bahrain. As technology continues to change lives it is also redefining how universities can create a lasting impact with their students.

\subsection{New Areas of Research and Innovation}

The area of renewable energy is a critical issue for both the MENA region and globally. GCC countries have seen rapid economic diversification and have become major energy consumers in their own right. Regional electricity consumption is growing at almost $8 \%$ a year, meaning generating capacity has to be doubled every decade. Gulf countries will require $100 \mathrm{GW}$ of additional power over the next 10 years to meet demand. Renewable energy offers Gulf countries a proven, home-grown path to reducing $\mathrm{CO}_{2}$ emissions. GCC countries are in the top 14 per capita emitters of carbon dioxide in the world (PWC, 2017). Renewables offer a financially viable way to change that. Renewable energy in the Middle East is therefore offering real potential for large-scale development projects. Middle East economies are now beginning to turn to new, more sustainable means of meeting their nations' increasing consumption.

Faced with volatile oil prices and international demand, the move into alternative energies is only going to increase. As projects in the Gulf take off, demand for both investment and the best energy professionals is expected to be high, especially in solar energy, in which the region has an obvious advantage.

The University must be at the leading edge of this shift and also the drive to clean energy though research and expertise, which is extended to an array of renewable energy sources such as wind, solar, waste and geothermal.

Changes in the energy sector on a global basis, which include regulatory pressures for green generation, a push to harness energy in the most efficient way, supply constraints and the ever-growing demand by consumers for lower cost, are currently driving a rise in the development of new technologies with the ultimate aim of providing a regional and global clean energy network that is more robust and secure than ever before.

Innovative technologies such as smart meters and battery storage are becoming an everyday feature for the commercial and residential customer. From data analytics to virtual power plants, there are big changes taking place in the way energy is distributed and consumed. As the pace of change accelerates, governments, universities, and the private sector will be under pressure to spread their investment. The University, as the leading research institute in Bahrain and one of the regional leaders in the area of clean energy and water resources, has a critical role in supporting the government to achieve the national renewable and energy efficiency targets. The 
University's ambition is to go beyond targets, and through sustainable partnerships, develop innovative solutions that have an impact on the environment, society, and the economy.

The key deliverables of current collaborations are:

- Capacity Building, through establishing University of Bahrain renewable energy labs, and preparing technicians and researchers.

- Research activities in the areas of energy and renewable energy, and water desalination and treatment.

- Training and workshops to disseminate the knowledge to society and those interested in the field of renewable energy from the private and public sectors.

\subsection{Smart Future}

One of the main components of the smart cities are the higher education institutions, and their role in human capital development and research and development to contribute to the advancement of ever smarter cities. The rise in smart cities or digital cities has been powered by certain trends, with around 68 per cent of the world's population expected to be urban residents by 2050 (UN DESA, 2018). The challenge to build more smart cities has become urgent. With the advent of digital technology and big data, changes are exponential, be it in public transportation, citizen services, or the way businesses are run.

Physical infrastructure from transportation systems to buildings, factories, and entire supply chains will sequentially be connected via the Internet. The Internet of Things means small computing devices are interweaved in the fabric of our environment. Services can be delivered through new platforms such as connected cars, smart homes, and connected public spaces, which ultimately leads to a better quality of life.

Smart cities will also require smart utilities. Sustainable energy consumption and 'green' energy production at home is becoming a new lifestyle. Today's hyperconnected consumer expects a reduced environmental footprint while still enjoying seamless services and ease of use, improving their quality of life through fully digitized processes that give them complete control over every aspect of their lives.

According to the International Data Corporation (IDC), 30 billion 'things' will be connected by 2020 (IDC, 2013). Everything from cars and appliances, to lights and temperature controls, will be connected in an interoperable network that will give consumers unprecedented control and choice over their use of their energy through the internet of things. The scale and pace of change is unrelenting. However, it's a challenge that academia must play a key part in and also move at speed to keep pace with rapid transformative change led by technology.

The University, through research, human capital developed, organizing Smart Cities Symposiums, and industry collaboration, is leading the drive for academia 
to understand the implications and opportunities for higher education. This can be achieved through the creation of research platforms, and extended collaborations.

Through collaborations and partnerships, the University also expects to create awareness about the future prospects of Smart Cities and serve as a platform to exchange ideas and learning through international case studies and best practice. The University is actively engaged in promoting a smarter Bahrain via its consultancy, and generating ideas and continuity, in the form of publications, and solving industry problems.

The University is preparing its graduate to work in current and future markets. Recently, the students participated in numerous local and global hackathons, competitions, projects, etc. Also in 2019, the Kingdom of Bahrain hosted Amazon Web Services Summit. The Summit included the first artificial intelligence hackathon, where 26 students from the University competed to provide solutions to real-world challenges. The focus in the participation in these kinds of competitions and hackathons is to develop digital skills for the students and improve their ability to innovate and invent.

\subsection{Discussion and Conclusion}

In 2016, the University of Bahrain embarked on challenging Transformation Plan. The Plan was developed to improve the impact of the University locally, regionally, and internationally. Corresponding, the University identified several key factors that will contribute to the successful implementation of the Transformation Plan, namely:

- Transformed Governance: in its pursue of excellence, the University need to modernized the decision-making and governance in the University. A review of its organizational structure was conducted to optimize and streamline processes.

- Research Excellence: the University focused not only to improve the number of publications and citation, but also on the impact of research locally, regionally, and internationally. The University established research partnership with international partners to build the national capacity in topics such as: renewable energy and water security. The result of this approach would lead to establishing the University of Bahrain as a flagship center of excellence in glocal research challenges and topics.

- Promotion Reform: academic promotion is linked to many aspects of institutional excellence. The University improved the planning, transparency of the process, and awareness of faculty members of the criteria. This resulted in improving the focus on individual faculty members and collectively improve the institutional output in areas related to promotion criteria.

- Financial Sustainability: the sustainability of the operations and services of the University is highly linked with its ability to self-generate income from a diverse set of sources. This is envisaged to gradually improve the funding projects, initiatives, activities, services, and academic programs when revenues are re-invested and systemically used. 
In conclusion, the future of higher education institutions is highly linked to the socioeconomic dynamics. It is, therefore, necessary that higher education institutions develop challenging strategies that comprises objectives to support their pursuit of excellence and address the future challenges and needs of learners, labor market, society, and economy.

\section{References}

Arab Forum for Environment and Development. (2017). Arab environment in 10 years. Beirut, Lebanon. Retrieved from http://www.afedonline.org/webreport2017/afedreport2017.htm.

Bahrain Economic Vision 2030. (2008). From regional pioneer to global contender: our vision: the economic vision 2030 for Bahrain. Retrieved from https://www.bahrain.bh/wps/wcm/ connect/38f53f2f-9ad6-423d-9c96-2dbf17810c94/Vision\%2B2030\%2BEnglish\%2B\%28low\% 2Bresolution\%29.pdf?MOD=AJPERES.

Bahrain Higher Education Council. (2014a). National higher education strategy 2014-2024: putting higher education at the heart of the nation. Bahrain Higher Education Council. Retrieved from http://www.moedu.gov.bh/hec/UploadFiles/Bahrain\%20Higher\%20Education\% 20Strategy\%20-\%20Summary.pdf.

Bahrain Higher Education Council. (2014b). National research strategy 2014-2024: creating a smart Bahrain based on knowledge \& innovation. Bahrain Higher Education Council. Retrieved from http://www.moedu.gov.bh/hec/UploadFiles/Bahrain\%20National\% 20Research\%20Strategy\%20-\%20Summary.pdf.

Green Metric. (2017). University rankings. Retrieved from http://greenmetric.ui.ac.id/overallranking-2017/.

Hamzah, R. Y., Alnaser, N. W., \& Alnaser, W. E. (2018). Accelerating the transformation to a green university: University of Bahrain experience. In E3S Web of Conferences Vol. 48, p. 06002.

IDC. (2013). Worldwide internet of things (IoT) 2013-2020 forecast: Billions of things, trillions of dollars. (IDC \#243661).

Bayt.com. (2017). Middle east skills report. Retrieved from https://www.bayt.com/en/researchreport-34825/.

PWC. (2017). Middle East megatrends: transforming our region. Price Waterhouse Cooper. Retrieved from https://www.pwc.com/m1/en/issues/megatrends.html.

University of Bahrain. (2016). Bridge to the future transformation plan 2016-2021. University of Bahrain.

United Nations Department of Economic and Social Affairs (UN DESA). (2018). 68\% of the world population projected to live in urban areas by 2050, says UN. Retrieved from https://www.un.org/ development/desa/en/news/population/2018-revision-of-world-urbanization-prospects.html.

UNESCO. (2017). United Nation sustainable development goals (SDGs). Retrieved from https:// www.un.org/sustainabledevelopment/sustainable-development-goals/.

World Economic Forum. (2017). The future of jobs and skills in the Middle East and North Africa. Switzerland. Retrieved from https://www.weforum.org/reports/the-future-of-jobs-and-skills-inafrica-preparing-the-region-for-the-fourth-industrial-revolution.

World Economic Forum. (2018). Global competitiveness report 2017-2018. Switzerland. Retrieved from http://www3.weforum.org/docs/GCR2017-2018/05FullReport/ TheGlobalCompetitivenessReport2017\%E2\%80\%932018.pdf. 
Open Access This chapter is licensed under the terms of the Creative Commons Attribution 4.0 International License (http://creativecommons.org/licenses/by/4.0/), which permits use, sharing, adaptation, distribution and reproduction in any medium or format, as long as you give appropriate credit to the original author(s) and the source, provide a link to the Creative Commons license and indicate if changes were made.

The images or other third party material in this chapter are included in the chapter's Creative Commons license, unless indicated otherwise in a credit line to the material. If material is not included in the chapter's Creative Commons license and your intended use is not permitted by statutory regulation or exceeds the permitted use, you will need to obtain permission directly from the copyright holder.

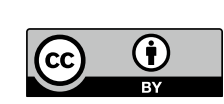

